\title{
Commentary The adrenocorticotropic hormone-induced cortisol response in acute pancreatitis
}

\author{
AB Johan Groeneveld
}

Department of Intensive Care, VUmc, 1082 AR Amsterdam, The Netherlands

Corresponding author: AB Johan Groeneveld, johan.groeneveld@vumc.nl

Published: 16 September 2009

This article is online at http://ccforum.com/content/13/5/186

(c) 2009 BioMed Central Ltd

See related research by Peng et al., http://ccforum.com/content/13/4/R123
Critical Care 2009, 13:186 (doi:10.1186/cc8018)

\begin{abstract}
The evidence that severe acute pancreatitis can result in critical illness-related corticosteroid insufficiency following impaired adrenal secretion is accumulating. The study by Peng and coworkers in Critical Care certainly contributes to that idea, even though the question whether relative adrenal insufficiency should prompt for treatment by substitution doses of corticosteroids remains unresolved. The study is discussed in terms of the risk factors, circumstances and significance of impaired corticosteroid secretion by adrenals in severe acute pancreatitis.
\end{abstract}

In a recent issue of Critical Care, Peng and coworkers [1] elegantly document a relatively low circulating cortisol response to adrenocorticotropic hormone (ACTH) stimulation in non-survivors (versus a normal response in survivors) of acute biliary pancreatitis. This was associated with more frequent bacteremia and severe disease. In fact, the ACTH-induced cortisol response inversely related to disease severity measures, as noted before [2]. None of the patients were treated by adrenal substitution doses of corticosteroids, even though often suffering from septic shock, as can be deduced from the data, likely associated with infection of pancreatic necrosis and subsequent bacteremia, as commonly occurs in severe cases [3]. Hence, it was suggested that insufficient adrenal cortisol secretion (reserve), relative to severity of disease, contributed to a poor outcome, reflecting critical illness-related corticosteroid insufficiency (CIRCl) even though baseline cortisol values did not differ between outcome groups.

Even though the recent Corticosteroid Therapy of Septic Shock (CORTICUS) study [4] does not suggest either the presence of $\mathrm{CIRCl}$ (as defined above) and a benefit of corticosteroid treatment in (relatively mild) septic shock, the concept can still not be refuted in view of a number of other studies documenting the issues in more severe septic shock $[2,5,6]$. Nevertheless, the question remains whether (septic) shock originating from pancreatitis would manifest differently than septic shock from other origins, and, thus, whether shock originating from pancreatitis would similarly benefit from corticosteroid treatment. To prove the latter, studies including large numbers of subjects are probably needed, so a definitive answer is unlikely to be provided in the near future. Therefore, current practise recommendations can only be based on the literature on 'general' septic shock, and substitution doses of corticosteroids are still considered useful in the early treatment of the syndrome according to a recent metaanalysis [6], particularly when associated with relatively low ACTH-induced cortisol responses [2] and in spite of the negative CORTICUS trial $[4,5]$.

A current study on pancreatitis [1] is also in line with the observed adrenal enlargement, probably caused by increased blood flow and haemorrhage/necrosis following intense stress-induced stimulation during acute pancreatitis, the exhausted secretion reserve upon ACTH stimulation noted before in pancreatic necrosis/infection associated with severe disease and non-survival, and the positive haemodynamic effects of substitution doses of corticosteroids, even in the absence of documented infection, reported by others [7-11]. Indeed, a direct role for $\mathrm{CIRCl}$ in contributing to pancreatic necrosis has been suggested $[8,10]$. Finally, there is experimental evidence for adrenal changes during pancreatitis, a role for phospholipase A2 in this condition and the benefit of low-dose cortisol administration in the development and ultimate outcome of necrosis $[1,10,12,13]$. However, we can not determine the cause and effect relationships from the associations reported by Peng and coworkers [9], since the independent predictive value for mortality of $\mathrm{ACTH}$-induced

$\mathrm{ACTH}=$ adrenocorticotropic hormone; $\mathrm{CIRCl}=$ critical illness-related corticosteroid insufficiency; CORTICUS = Corticosteroid Therapy of Septic Shock. 
cortisol responses was not studied. Such predictive value, independent of other markers of disease severity, would indeed argue in favour of a contributory role of $\mathrm{CIRCI}$ in outcome and treatment by substitution doses of corticosteroids. Moreover, optimal cutoff levels in ACTH-induced cortisol responses with the highest predictive values for outcome are missing, and the increase of $<250 \mathrm{nmol} / \mathrm{l}$ (9 $\mathrm{mg} / \mathrm{dL})$, found to discriminate in other studies $[4,6,10]$, was used as the cutoff to denote $\mathrm{CIRCl}$, even though it is dependent, almost by definition, on the severity of disease [2].

Notwithstanding some limitations, the study in Critical Care by Peng and coworkers [1] supports the idea that acute (necrotic/infected) pancreatitis can result in $\mathrm{CIRCI}$ following relative adrenal insufficiency, that the ACTH test can help to recognise it, and that the condition likely warrants treatment with substitution doses of corticosteroids. More data are welcome that can be included in a systematic analysis to confirm these ideas.

\section{Competing interests}

The author declares that they have no competing interests.

\section{References}

1. Peng Y-S, Wu C-S, Chen Y-C, Lien J-M, Tian Y-C, Fang J-T, Yang C, Chu Y-Y, Hung C-F, Yang C-W, Chen P-C, Tsai M-H: Critical illness related corticosteroid insufficiency in patients with severe acute biliary pancreatitis: a prospective study. Crit Care 2009, 13:R123.

2. De Jong MF, Beishuizen A, Spijkstra JJ, Groeneveld AB: Relative adrenal insufficiency as a predictor of disease severity, mortality, and beneficial effects of corticosteroid treatment in septic shock. Crit Care Med 2007, 35:1896-1903.

3. Besselink MG, Van Santvoort HC, Boermeester MA, Nieuwenhuis VB, Van Goor H, Dejong CHC, Schaapherder AF, Gooszen HG; for the Dutch Acute Pancreatitis Study Group: Timing and impact of infections in acute pancreatitis. Br J Surg 2009, 96: 267-273.

4. Sprung $C L$, Annane D, Keh D, Moreno R, Singer M, Freivogel K, Weiss YG, Benbenishty J, Kalenka A, Forst H, Laterre PF, Reinhart K, Cuthbertson BH, Payen D, Briegel J; CORTICUS Study Group: Hydrocortisone therapy for patients with septic shock. N Engl J Med 2008, 10:111-124.

5. Groeneveld AB, Molenaar N, Beishuizen B: Should we abandon corticos- teroids during septic shock? No. Curr Opin Crit Care 2008, 14:384-389.

6. Annane D, Bellissant E, Bollaert P-E, Briegel J, Confalonieri M, De Gaudio R, Keh D, Kupfer Y, Oppert M, Meduri GU: Corticosteroids in the treatment of severe sepsis and septic shock in adults. JAMA 2009, 301:2362-2375.

7. Eklund A, Leppäniemi A, Kemppainen E, Petillä V: Vasodilatory shock in severe acute pancreatitis without sepsis: is there any place for hydrocortisone treatment? Acta Anaesthesiol Scand 2005, 49:379-384.

8. Muller CA, Vogeser M, Belyaev O, Gloor B, Strobel O, Weyhe D, Werner J, Borgstrom A, Buchler MW, Uhl W: Role of endogenous glucocorticoid metabolism in human acute pancreatitis. Crit Care Med 2006, 34:1060-1066.

9. Bollen TL, van Santvoort HC, Besselink MG, van Ramshorst B, van Es HW, Gooszen HG; Dutch Acute Pancreatitis Study Group: Intense adrenal enhancement in patients with acute pancreatitis and early organ failure. Emerg Radiol 2007, 14: 317-322.

10. De Waele JJ, Hoste EAJ, Baert D, Hendrickx K, Rijkaert D, Thibo $\mathrm{P}$, Van Biervliet $\mathrm{P}$, Blot SI, Colardyn F: Relative adrenal insufficiency in patients with severe acute pancreatitis. Intensive Care Med 2007, 33:1754-1760.

11. Motallabzadeh R, Godfrey E, Jamieson NV: Diagnostic dilemna of adrenal enlargement after acute pancreatitis. Ann $R$ Coll Surg Engl 2008, 90:1-3.

12. Muller CA, McArthur N, Belyaev O, Burr W, Werner J, Meiser A, Weyhe $D$, Büchler MW, Uhl W: The effect of synacthen on acute necrotizing pancreatitis in rats. Pancreas 2008, 37:316320.

13. Xu S, Chen C, Wang W-X, Huang S-R, Yu J, Chen X-Y: Crucial role of group lla phospholipase A2 in pancreatitis-associated adrenal injury in acute necrotizing pancreatitis. Path Res Practise 2009 , in press. 